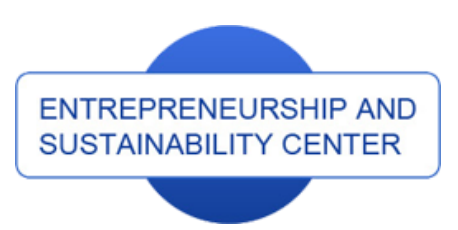

Publisher

http://jssidoi.org/esc/home enterprise

europe

network

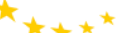

Business Support on Your Doorstep

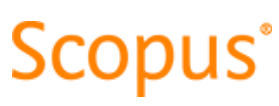

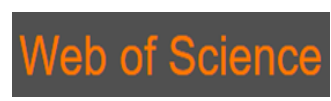

Clarivate
Analytics

\title{
DARK TRIAD CHARACTERISTICS BETWEEN ECONOMICS \& BUSINESS STUDENTS IN CROATIA \& SLOVAKIA: WHAT CAN BE EXPECTED FROM THE FUTURE EMPLOYEES?
}

\author{
Mario Bogdanović1, Milota Vetráková ${ }^{2}$, Stanislav Filip ${ }^{3}$ \\ ${ }^{1}$ Independent author, Serdara Vučkovića 16, 21230 Sinj, Republic of Croatia \\ ${ }^{2}$ Faculty of Economics, University Matej Bel, Tajovského 10, 97590 Banská Bystrica, Slovak Republic \\ ${ }^{3}$ School of Economics and Management in Public Administration, Furdeková 16, 85104 Bratislava, Slovak \\ Republic \\ E-mails: ${ }^{1}$ mbogdan2011@gmail.com, ${ }^{2}$ milota.vetrakova@umb.sk, ${ }^{3}$ stanislav.filip@vsemvs.sk
}

Received 20 February 2018; accepted 25 March 2018; published 30 June 2018

\begin{abstract}
This paper deals with the "dark triad" personality and its components (Machiavellianism, narcissism, subclinical psychopathy) on economics \& management student population in Croatia and Slovakia. Dark Triad represent important HRM area in which is trying to understand the "dark" side of human functioning which has potentially harmful impact on organization functioning and performance. Population of economics \& management students is important in the context of HRM because of their future high potential to generate dysfunctional organizational behaviors, when they will be organizational employees, especially on management positions. The goal of this research was to gather the data about dark triad personality phenomenon, make the comparisons between Croatian and Slovak sample, present the potential organizational impact of employees with dark characteristics in organizational context and show the implications for HRM. For measurement of the dark triad components (variables) it is used questionnaire measurement that adopts the standardized short dark triad measurement instrument of Jones \& Paulhus. Results of the Croatian students are compared with the results of Slovak students, and basically also with Canadian student sample. The basic results showed that $6 \%$ Croatian and $0.5 \%$ of Slovak economy \& management students showed full dark triad profile, also there are found very significant statistical differences in the Machiavellianism and subclinical psychopathy variables between the Croatian and Slovak samples, i.e. these characteristics were statistically higher in Croatian sample.
\end{abstract}

Keywords: Dark triad (Machiavellianism, narcissism, psychopathy); HRM; management; comparative analysis; Croatian; Slovaks

Reference to this paper should be made as follows: Bogdanović, M., Vetráková, M., Filip, S. (2018). Dark triad characteristics between economics \& business students in Croatia \& Slovakia: what can be expected from the future employees? Entrepreneurship and Sustainability Issues 5(4): 967-991. http://doi.org/10.9770/jesi.2018.5.4(19)

JEL Classifications: M12, M5

Additional disciplines: psychology; sociology; law 


\section{Introduction}

For organization and management is important to know every factor which create optimal conditions for increasing the efficacy of working force/employees. In such a context employers and HRM professionals are interested to know which desirable characteristics employees should have, and what to do if they do not have such desirable characteristics, or what to do when they even have negative, e.g. dark triad characteristics. From the important characteristics, which had important impact on working behavior in organizations, meta-analytic researchers showed that personality is moderately strong predictor in solving working tasks (e.g. intelligence is a very strong predictor), whilst motivation mechanisms moderates between personality traits and working performance (Barrick \& Mount, 1991; Siller \& Cibak, 2016). But, it is also showed that it is very important to understand "dark side" personality which can have significant (mostly negatively) impact in organizational context. Therefore, the interest of researchers in the last ten years shifts from the bright side employee's personality (e.g. five factor personality model - "Big five" relates to the independant personality traits: neuroticism, extroversy, oppeness, compliance, conscientouous (Lee \& Ashton, 2005) to the dark side personality (cf. Baboselac-Marić, 2015). Also, it is important to note, that in any organization reality there is no organization that doesn't embody some form of pathology (Hawley according to Lučić, 2013).

This organizational pathology arises because of negative workplace behavior whose source is mostly in personal traits (e.g. dark triad traits). Namely, the strongest predictor of an employee's behavior (in general and in organizational sense) is his/her personality. So, personal traits as integrity, authenticity, and optimism support positive behavior and positive outcomes, while negative personal traits are associated with negative workplace behaviors (O'Boyle et al., 2012). Negative or counterproductive work behaviors like theft, leader derailment, organizational politicking, mobbing, manipulation, sadism, etc. can have deleterious consequences for organizations in terms of organizational outputs such as performance, profit, and reputation. Dark triad personalities are more prone to do such criminal and/or unethical behavior. So for HRM is very important to understand the dark side of personality which reside in the area between normal personality and clinical pathology (defined disorder in psychiatric classification of DSM-IV) (Spain, Harms \& Lebreton, 2013), because of the fact that the components of dark triad relates on this what is consider as normal i.e. subclinical level (abnormal is treated in term ,clinical“ which depicts persons which are in clinical or forensic treatment/surveillance and term „subclinical“ relates to „softer version“ and cover broader span of behaviors and functioning in the population). In such a context the approach to the subclinical traits of personality is called Dark Triad which has the impact on research in the area of normal personality by aberrant/dysfunctional/maladaptive patterns of organizational behavior and functioning (Paulhus \& Williams, 2002).

\subsection{Concept of Dark triad and "toxic triangle" in organizational settings}

Defined in most simple way dark triad is the combination of predispositions which include non-sensitiveness (for others) and covetousness, and relate to the model of behavior by which is taken the advantage over others, exploitation the others because of his selfish interests (Jones \& Paulhus, 2011). Dark triad with components: Machiavellianism, narcissism and subclinical psychopathy (Paulhus \& Williams, 2002), is based on malevolent character and social behavior which goal is to promote himself whereat is making the damage to others. Psychopathy, narcissism and Machiavellianism are three personality types which, in isolation, are bad enough, but in combination are utterly toxic. The dark triad is the set of three personality constructs considered to be socially aversive: subclinical psychopathy, Machiavellianism, and subclinical narcissism (Paulhus \& Williams, 2002), so the dark triad is the term used to describe the combination of these three dark traits (Plumridge, 2013). They can be characterized by a lack of empathy, a willingness to manipulate others (for self-betterment), antagonism, and a 
belief in one's own superiority (Paulhus \& Williams, 2002). What do these three toxic personality traits represent?

Machiavellianism indicates a manipulative personality. Machiavellians overtly manipulate and exploit people for their benefit. Machiavellians have cynical disregard for morality and engage in deception. They are skilled in negotiating and enjoy combat. They are good in forming political alliances, influencing others for their own gain, using flattery or deceit; if necessary, they use subtle skills to gain influence. But they can also be charismatic leaders and forceful negotiators. They can be creative because they often enjoy testing limits.

Narcissism characterizes individuals/personalities who want to become the center of attention, seek prestige, who are characterized by grandiosity, entitlement, dominance, superiority and status with egotism that knows no bounds. They use appearance, ingratiating tactics, and phony compliments to get what they want. They are often skilled at making a good first impression, and people who can engagingly tell stories and impress others. Because of that behavior, they are at least initially respected and put in positions of authority and command by others.

Psychopathy indicates antisocial personality which is impulsive, thrills seeking, aggressive, tends towards antagonism and lacks remorse and empathy. People look like hostile, harsh or arrogant; they can also be sadistic. They think rules don't apply to them. But they get their way through their superficial charming manner but also they tend to think creatively, testing the limits. They are also skilled manipulators (forming political alliances). They tend to focus on short-terms benefits for themselves rather than long-term results for their organization (Malnick, 2013; Plumridge, 2013; Jonason et al., 2012; Jones and Paulhus, 2012; O'Boyle et al., 2012; Yatzeck, 2012). The dark triad scheme with correlations between its basic components is presented in the picture 1.

Picture 1. The Dark Triad with the relationships between the components of dark triad

\section{PSYCHOPATHY}

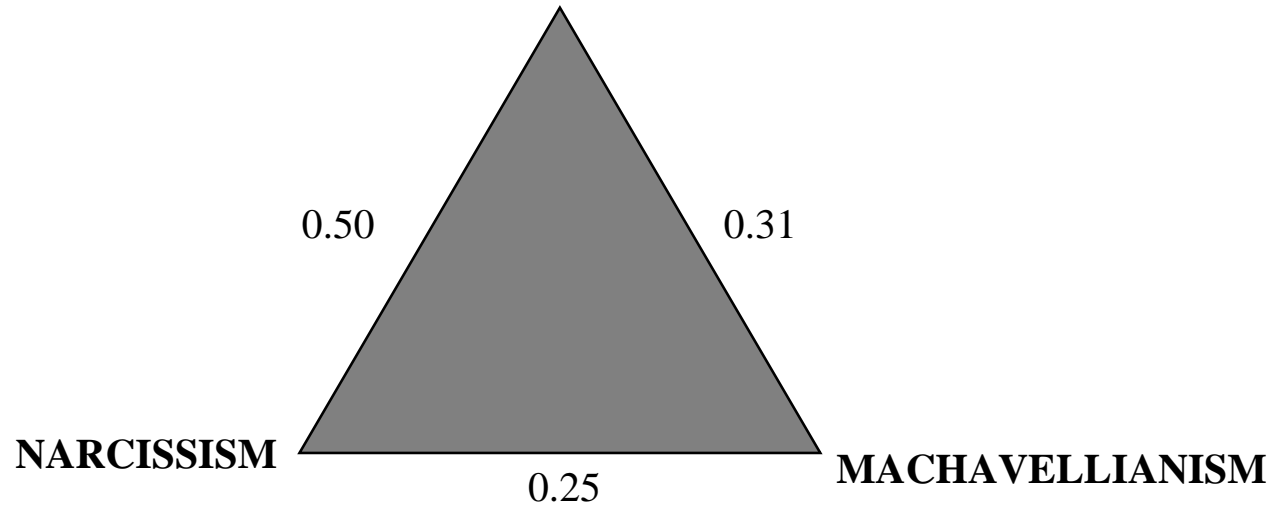

Source: McHoskey, Worsel \& Szyarto, 1998 (intercorrelation between narcisism and psychopathy, intercorrelation bethween psychopathy \& Machiavellianism); Paulhus \& Williams, 2002.

As can be seen from the picture all three components have some empirical overlap (Furnham, Richard \& Paulhus, 2013). A person who shows consistently high results of narcissism i.e. ruthless self-promotors shows also high results on psychopathy (Gustafson \& Ritzer, 1995). But the difference between narcissism and psychopathy is in the love and deeper emotions (narcissists would like to change his personality to receive love from others, subclinical psychopaths no, because they are not able for love, deeper emotions, so consider that there is not needed their personality change) (Boddy, 2011). Narcissism correlates negative with the need for intimacy (Jonason \& Krause, 2013). Machiavellianism construct is developed in 1970 (Christie \& Geis, 1970), is positively 
The International Journal

ENTREPRENEURSHIP AND SUSTAINABILITY ISSUES

ISSN 2345-0282 (online) http://jssidoi.org/jesi/

2018 Volume 5 Number 4 (June)

http://doi.org/10.9770/jesi.2018.5.4(19)

connected with psychoticism and extraversion (Allsopp, Eysenck \& Eysenck, 1991 according Corral \& Covette, 2000), with paranoia and narcissism (McHoskey, Worzel \& Szyarto, 1998), negatively connected with the trait complacence (Jackobwitz \& Egan, 2006; Paulhus \& Williams, 2002), and consciousness (Baboselac-Marić, 2015). The weakest relationship is between Machiavellianism and narcissism but it exists, because those high in Machiavellianism more often talks about himself in superlatives and negatively on the others. According to Furnham (2010), three interrelated features of the dark side are:

1. Arrogance, self-centeredness, self-enhancement;

2. Duplicitousness, cynism, manipulativeness;

3. Emotionally cold, impulsive thrill-seeking and frequently engage in illegal, dangerous, anti-social behavior.

Dark side managers cheat and lie; they plagiarize and are known for their social deviance, but it is usually never extreme enough to warrant either imprisonment or even dismissal (Furnham, 2010). When organizations have manager(s) who score high on combined psychopathic, Machiavellian and narcissistic tendencies, it can be recognized by the following behaviors (Malnick, 2013):

1. They tend to exploit and trick others for self-advancement.

2. They have used lies and deception to get their way.

3. They have used ingratiation to get their way.

4. They tend to manipulate other for selfish reasons.

5. They tend not to feel regretful and apologetic after having done wrong.

6. They tend not to worry about whether their behavior is ethical.

7. They tend to be lacking in empathy and crassly unaware of the distress they can cause others.

8. They tend to take a pretty dim view of humanity, attributing nasty motives and selfishness.

9. They tend to be hungry for admiration.

10. They tend to want to be center of attention.

11. They tend to aim for higher status and signs of their importance.

12. They tend to take it for granted that other people will make extra efforts to help them.

All three constructs of the dark triad are high in striving for autonomy and superiority (agency) and low in connecting with and helping others (communion), and all three are high in ruthless self-advancement (Zuroff et al., 2010). Psychopaths score high on the impulsivity dimension; narcissism stands apart on the axis of superior identity (i.e. self-enhancement). For narcissism, the strongest associations are with low modesty and low straightforwardness, whereas psychopathy associations are strongest with low deliberation and low dutifulness.

The strongest correlates of narcissism are achievement-striving and competence, whereas the strongest correlates of psychopathy are low dutifulness and low deliberation (Furnham, Richardson \& Paulhus, 2013, p. 203-204). Further, all three dark triad constructs are positively correlated with lying, dominance and sadism (Bradlee \& Emmons, 1992; Chabrol \& al., 2009). Dark triad traits help people "get ahead" of but not necessary "get along" with others at work (Furnham, Richardson \& Paulkus, 2013, p. 206). For destructive organizational climate bad leaders are often not enough but they need followers which "conspire" with the bad leader and particular situation. The "toxic organizational triangle" is presented in picture 2. 
Picture 2. The toxic organizational triangle: elements in three domains related to destructive leadership in organizational setting

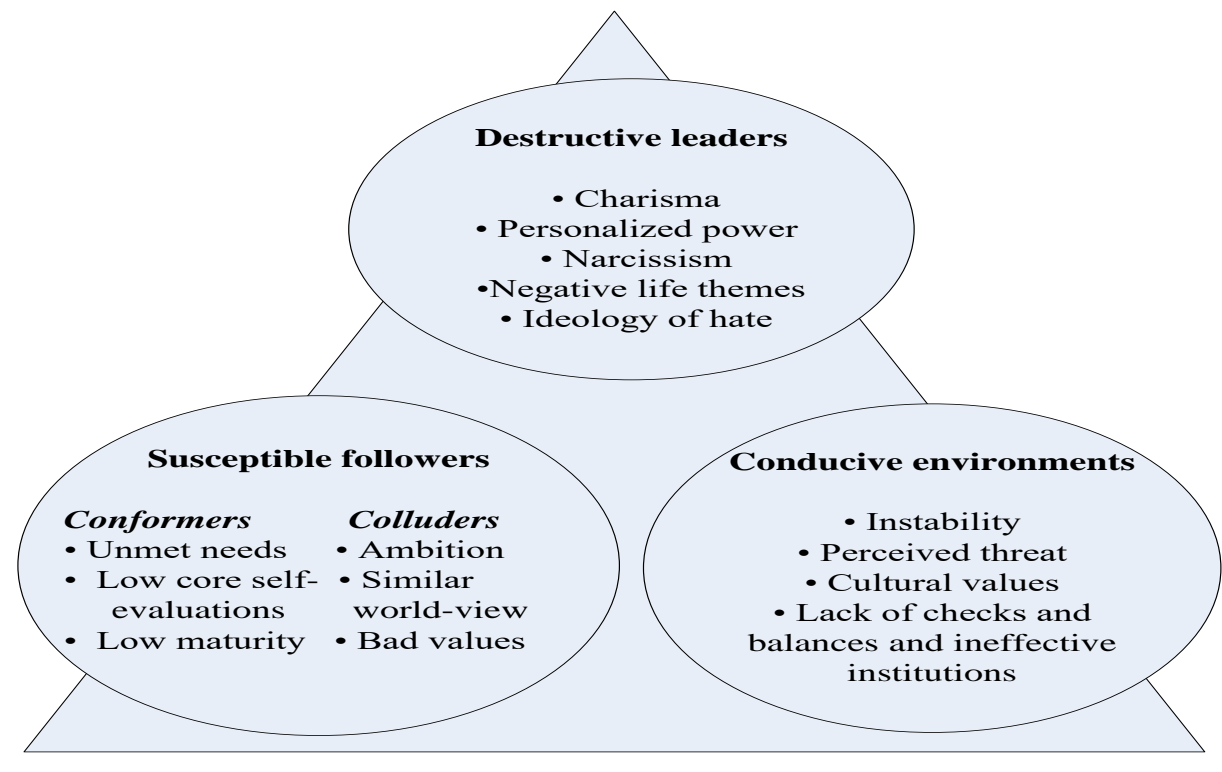

Source: Furnham (2010)

In picture 3, we present a more complex picture of the toxic triangle surrounding dysfunctional leadership and organizations where dark triad personality traits have an important place.

Picture 3. Elements of the organizational toxic triangle surrounding dysfunctional leadership and organizations where dark triad personality traits have an important place

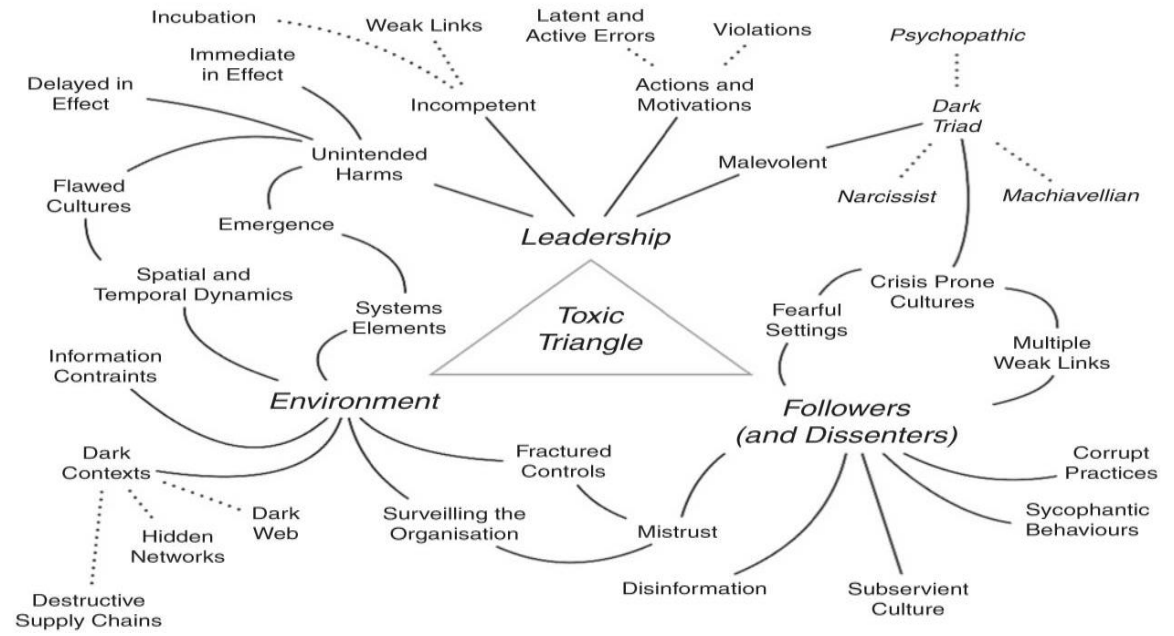

Source: Fisherbacher-Smith, (2015)

Although the picture of the toxic organizational triangle seems very complex it is important to understand this organizational phenomenon because dark triad personalities are utterly toxic for organizational culture/climate and can produce very bad organizational outcomes (even the "death of the organization"), so is very important to 
familiarize with it not only to understand it but also to deal with it in order to improve organizational HR functioning.

\subsection{Impact of dark triad on organization and organization efficacy}

Managers and other employees who score high on the dark triad (toxic employers) use hard (e.g. threats) and soft tactics (e.g. offering compliments or joking/kidding) to manipulate the person and the situation (Jonason at al., 2012). Namely, psychopathy in a work setting was related to the use of charm and coercion, Machiavellianism was related to the use of charm and seduction, and narcissism was related to invoking feelings of responsibility in others. Specifically, psychopaths and Machiavellians use direct and hard manipulation such as the use of threats, whereas narcissist and some Machiavellians employ softer methods of exploitation such as using compliments to ingratiate themselves with their fellow employees and then asking for "favors" (Black, 2013). Whereas narcissist claim to use soft manipulation tactics, psychopaths choose hard tactics, Machiavellians are the most flexible and use both soft and hard tactics. Dark triad is considered to be especially harmful when the organization is given the positional power of the individuals concerned and are typified by a "systematic and repeated behavior by a leader, supervisor or manager that violates the legitimate interest of the organization by undermining and/or sabotaging the organization's goals, tasks, resources, and effectiveness and/or the motivation, well-being or job satisfaction of subordinates" (Einarsen at al., 2007). A bad, toxic or pathological organizational situation is caused by the employees; it is real and it is dangerous, especially if it is present in management or business leadership. In fact, $1 \%$ of normal people could be classified as psychopaths, rising to 4\% in CEO's and business leaders, and 15-25\% of male offenders in federal correctional settings (Black, 2013; Chopra, 2013; Yatzeck, 2012). In 2008, it was estimated that $6.2 \%$ of the population met the DSM-IV-TR criteria for narcissism (Black, 2013). Individual studies found that narcissists in positions of power often engage in unethical behavior, psychopaths are a detriment to a company's productivity and are poor at cooperating with colleagues, Machiavellians are abusive and manipulative within the workplace and have demonstrated a diminished organizational commitment and poor supervisory responsibility (Black, 2013).

For HRM is important to know the relationship between dark triad and work performance. A meta-analysis of 43.907 articles published about dark triad individuals in the workplace between 1951 and 2011 revealed that job performance was negatively related to Machiavellianism and psychopathy, and the possession of all three dark triad traits in employees was moderately related to bad productivity in the workplace (O'Boyle at al., 2011). In organizational settings, one or more of the dark triad personalities have counterproductive behavior. They are evident in the notions of "toxic leadership", "snakes in suits", "bad bosses", "shark-managers". The same applies to non-leaders as well. The examples of organizational settings where high levels of dark triad traits combined with other factors such as intelligence or physical attractiveness (which often help an individual acquire positions of leadership) are also known. Toxic employees, as embodied by the dark triad traits, represent problems for any company/organization, supervisors, and fellow employees. This includes disintegration of teamwork performance and of organizational effectiveness (Boddy, 2015). Because leaders unite, direct, and coordinate people to achieve a goal, destructive leaders can be extremely dangerous (in interactions with followers and conducive environment, they can even destroy organizations), so it is important to learn how those employees (managers and others) who score high on the dark triad traits behave at work, and what preventive measures to be taken. The empirical evidence in transition organizations and economies has shown that bad management/leadership which can be at least attributed to the dark triad personalities (Machiavellianism, narcissism, psychopathy) is responsible for bad organizational and socio-economic results. For example, in "big business" just the cases of Enron, Lehman Brothers, Worldcom, Freddie Mac, Bernie Madoff, and plenty of other multibillion dollar fraud cases have drawn the attention of the public and researchers to the Dark Triad traits, and negative consequences of such traits in the workplace (Jonason et al., 2015). For organizational success, it is extremely important to have management/business leadership without such pathological personalities. Components of dark triad relate to 
weaker self-control, manipulative behavior in organizational settings, and that persons with these characteristics are in the "grey" zone of "toxic employees" or "rotten apples" (Penny \& Spector, 2002; Robinson \& O'LearyKelly, 1998 according Jonason, Wee \& Li, 2015). Therefore, it is very important to make steps toward knowing and preventing and reacting on the dark triad personalities and such behavior especially by management/business leadership.

\subsubsection{Machiavellianism in the organizational context}

Persons who are prone to Machiavellianism express job satisfaction when they consider that they are doing high prestigious and jobs with high authonomy (Jonason, Wee \& Lee, 2015). But when they are working in high competitive conditions they report about general job dissatisfaction. So, competitive persons have tendencies to choose less competitive environment to be satisfied on the job but in the same time perceive that the competition is always and everywhere present. Machiavellianism shows strong connectivity with counter-productivity working behavior (Dahling, Whitaker \& Levy, 2009), and the persons prone to Machiavellianism report about lower level of job satisfaction and perceives more stress on the job. The same authors think that this lower job satisfaction and higher stress has his source in their constant effort for awards and approvals and control of others. Machiavellians perceives the world around them as competitive and this perception is in the function of the approach oriented on the power. They show a lack of empathy, social interests and prosocial behavior. They think that it is wise to talk to the people what they want to hear, that people are unfair, without honesty/integrity and that to them can't be belived (McHoskey, Worzel \& Szyarto, 1998). By their behavior of "social chameleons" they can build strong social network in the organization, acquire the trust of coworkers and can produce the desirable outcomes, until the mask of manipulation is not recognized. When manipulation behaviors are recognized, most often by intelligent coworkers their impact weaken and can produce organization dis-cohesion and negative organization results (Bogdanović, 2016).

\subsubsection{Narcissism in the organizational context}

Narcissism is described as behavior directed to himself-admiration, praise himself, self-adoration ("ego" in Freuds terms) and such affinity relates to non-ethical organizational behavior and need for power (Rosenthal \& Pittinsky, 2006 according Jonason, Slomski \& Partyka, 2011). Although some level of narcissism is needed for normal functioning because it makes balance between foreign and his own needs, extreme subclinical narcissism behavior can have negative impact on organization in terms of team work (cooperation/collaboration). Namely although narcissist are not necessarily unproductive they are often negatively perceived from their working environment (O’Boyle \& al. 2012). Narcissism affinity obstruct teamwork and disable cooperative behavior, although narcissism persons see himself as very positive, others perceive them as non-cooperative and aggressive. Narcissism persons believe that they are better than the others, that they deserve more respect and admiration of others, can be extremely vanish, arrogant, have exaggerated feeling for "their rights" (Cale \& Liliefeld 2006 according Boody, 2011), in the leader role overestimate their efficiency and underestimate the efficiency of other employees (Judge, LePine \& Rich, 2006). High level of narcissism in organizations relate to general dissatisfaction (Koppelman \& Mullins, 1992). So it is to consider that narcissistic persons have strong feeling of inferiority so they can't be satisfied with their life. As indicator of poor working performance of narcissism employees can be the negative correlation with empathy and consciousness (Paulhus \& Williams, 2002; Barrick \& Mount, 1991). Persons with high narcissism in the working environment often do not satisfy their needs, what is also suboptimal for the organization in terms of their lower motivation.

\subsubsection{Subclinical psychopathy in the organizational context}


Persons with subclinical psychopathy are exclusively focused on achievement by which they are not embarrassed by the empathy or possible victims (sacrifices) which are the results of such motivation. Subclinical psychopathy can bring to the lower level of organizational responsibility and have negative impact on productivity (Boddy, 2010 according Jonason, Slomsky \& Partyka, 2011). Some research confirmed the connection of psychopathy with low level of consciousness (Miller \& Lynam, 2003). Because of higher level of impulsivity, they work weaker than the others. Their impulsive behavior often can be destructive, so by such a person is increased the affinity to fake and sabotage (O'Boyle \& al., 2012). High level of boredom make them prone to risky activities, they do not respect the rights of other people, very often they do not respect deadlines, are careless and consider that most of their responsibilities are not their responsibility. Psychopathy is in the most extent connected with violence and aggressive behavior, to them is not important that the coworkers accept them, and they do not endeavor to establish good relationships with others. So subclinical psychopaths are not at all a good solution for any organization.

\subsection{Research purpose and goals/problems}

This research has a purpose to achieve the greater awareness of the dark triad organizational problem, with an emphasis on organizational measures to prevent and diminish it. The first step is the organizational diagnosis (recognition) of such behavioral traits and then providing the measures (preventive and reactive) against such pathological organizational behavior. This research is a step in eliminating/diminishing such a problem in organizations. The main aim of this research was to explore the dark triad personality traits of the economic \& management student population in Croatia \& Slovakia, compare them, and also make the comparison with the Canadian students (as control group) and to propose basic measures to reduce the dark side's effects in the organizational future. The research problems are defined as follows:

A) To identify the items from the Croatian \& Slovak sample that have high values in dark management triad component variables (Machiavellianism, narcissism and subclinical psychopathy) according the criterion made on Canadian student sample $(\mathrm{N}=387)$ from research of Jones \& Paulhus 2012.

B) To compare the deviant management scales (Machiavellianism, narcissism and subclinical psychopathy) between the Croatian sample $(\mathrm{N}=150)$, Slovak $(\mathrm{N}=185)$ and the Canadian sample $(\mathrm{N}=387)$ from the research of Jones \& Paulhus (2012).

C) To examine how much persons, have potential harmful Machiavellianism, narcissism and subclinical psychopathy and extremely harmful whole psychological Dark side profile (very high level of Machiavellianism, narcissism and subclinical psychopathy) in Croatia \& Slovakia.

D) To examine if there is a statistically significant difference in the variables of Machiavellianism, narcissism and subclinical psychopathy between male and female management students, also between students who works during the study with students who do not work during their study also, in the Croatian \& Slovakian sample.

Finally, the goal of this research is to discuss the possible causes of obtained results on the Croatian \& Slovak sample and give practical implications for HRM and general organizational management how to deal with dark side's personalities in order to avoid or diminish their potential future negative effects in organizations. This research use known short dark triad measurement instrument and methodology which is similar to the way of research which performed the other authors e.g. Malesza at al. 2017; Jones \& Paulhus, 2012; Paulhus \& Jones, 2011; Jonason \& Webster, 2010; Paulhus \& Williams, 2002. 


\section{Methodology}

Because there is little evidence on the "dark triad in business" and deviant organizational behavior and deviant values (virtues) in transition economies i.e. Croatia \& Slovakia, the authors consider that such topic (although interesting and for management and organizations very relevant) can be treated as a new line of research. This work has its foundation in a sample of economics \& management students from the Faculty of Economics at the University of Split in Croatia - hereafter referred to as Croatian sample, and economy and management students of Faculty of Economics University Matej Bel in Banska Bystrica, Slovakia - hereafter referred to as Slovakian sample. The goal was to research and to compare the frequency of "dark management triad" (variables Machiavellianism, narcissism, psychopathy) of these two samples (Faculty of Economics at the University of Split, which hosts about 4.000 students and Faculty of Economics Matey Bel University in Banska Bystrica, Slovakia which host about 3.000 students) which also educates future management professionals. The Canadian sample (basically referred by researcher Jones \& Paulhus 2012; 2014) is treated as control sample. The benefit of such type of research is that it can forecast the future economic efficiency of such human resources, and prevent the possible bad economic outcomes in different types of organizations.

\subsection{Measurement instruments}

The traditional measures of the Dark Triad together require approximately 100 traits, so when time is limited and can cause fatigue by the several participants researchers can use a brief measure (Gosling, Rentfrow \& Swan, 2003) which can be useful. In this research so it is used the Short Dark Triad to measure the dark personalities. This 27 -item instrument has been employed successfully by a number researchers (e.g. Arvan, 2011; Baughman et al., 2011). The short dark triad questionnaires (Jones \& Paulhus, 2012; 2014) has nine items of Machiavellianism, nine items of narcissism and nine items of psychopathy. The dark triad questionnaire used the five degree Likert scale. The original questionnaire is attached in the appendix. For the purposes of the research on the Croatian population sample, the basic questionnaire was translated into Croatian, and for Slovak sample it was translated on Slovakian. The descriptive statistics of the questionnaire on the Canadian student population $(\mathrm{N}=387)$ is presented in table 1 and table 2.

Table 1. Psychometric norms for dark triad variables

\begin{tabular}{|l|c|c|c|}
\hline & Mean & S.D. & Alpha \\
\hline Machiavellianism & 3.1 & .76 & .78 \\
\hline Narcissism & 2.8 & .88 & .77 \\
\hline Psychopathy & 2.4 & 1.0 & .80 \\
\hline
\end{tabular}

Source: Jones \& Paulhus (2012)

From the presented norms, it can be seen that all three variables (Machiavellianism, narcissism and psychopathy) have good reliability (Cronbach Alpha for all the three variables was between 0.78-0.80). 
Table 2. Intercorrelations between the main three dark triad variables

\begin{tabular}{|l|l|l|l|}
\hline & Machiavellianism & Narcissism & Psychopathy \\
\hline Machiavellianism & -- & .23 & .37 \\
\hline Narcissism & & -- & .20 \\
\hline Psychopathy & & & -- \\
\hline
\end{tabular}

Source: Jones \& Paulhus (2012)

The dark triad measurement instruments exhibited a relatively low degree of intercorrelation (e.g. the intercorrelation between Machiavellianism and narcissism here was much lower than in previous research of Paulhus \& Williams 2002 presented in picture 1., so we can conclude that this newer measurement instrument is improved and better measure the construct components), so it can be considered that the dark triad variables are rather "pure", not only conceptual but also empirical concepts. Some of the past studies suffered from measurement issues, i.e. empirical overlap; for example, subclinical psychopathy and narcissism loaded on the same factor (Furnham \& Crump, 2005, Furnham \& Trickey, 2011; according to Furnham, Richards \& Paulhus, 2013, p. 202).

Interesting correlations presented between Dark triad measures (measured with short dark triad measurement instrument like is done in this paper) found the research on larger sample (N=913) German adolescents. Although the sample of adolescents (13-18 years) are not the same with adult samples of young students (18-23 years) from the table 3. can be seen the main empirical characteristics (quality) of this measurement instrument.

Table 3. Convergent correlations between traditional three measures of the Dark Triad and Short dark triad measures

\begin{tabular}{|c|c|c|c|}
\hline & SHORT & DARK & TRIAD \\
\hline Standard measures & Machiavellianism & Narcissism & Psychopathy \\
\hline SRP III-Manipulation & $.58^{* *}$ & $.39^{* *}$ & $.67^{* *}$ \\
\hline SRP III-Callous Affect & $.49^{* *}$ & $.24^{* *}$ & $.58^{* *}$ \\
\hline SRP III-Erratic Lifestyle & $.33^{* *}$ & $.34^{* *}$ & $.59^{* *}$ \\
\hline SRP III- Antisocial Behavior & $.19^{*}$ & $.20^{*}$ & $.61^{* *}$ \\
\hline NPI-Leadership/Authority & $.35^{* *}$ & $.51^{* *}$ & $.49^{* *}$ \\
\hline NPI-Exploitative/Entitlement & $.26^{* *}$ & $.49^{* *}$ & $.38^{* *}$ \\
\hline Mach IV-Machiavellian Tactics & $.52^{* *}$ & $.31^{* *}$ & $.52^{* *}$ \\
\hline Mach IV-Cynical Worldview & $.55^{* *}$ & .11 & $.33^{* *}$ \\
\hline
\end{tabular}

Source: $\mathrm{XY}$, forthcoming, under revision

SRP-III = Self-Report Psychopathy Scale-III; Mach-IV = Machiavellianism Scale; NPI = Narcissistic Personality Inventory; *p < .05; **p $<.001$.

It can be concluded that short dark triad measure instrument is very good measurement instrument although it has some empirical overlaping in constructs content, e.g. Machiavelians and Psychopaths both were similar in the facet of Manipulation ( $\mathrm{r}=0.58 \mathrm{vs} \mathrm{r}=0.67)$ and Machiavelian Tactics $(\mathrm{r}=0.52 \mathrm{vs}$ $\mathrm{r}=0.52$ ). Narcissist were similar with Psychopaths in Leadership/Authority ( $\mathrm{r}=0.35$ vs 0.49) and Machiavellianist ware very similar with Narcissist in the facet of Erratic lifestyle ( $\mathrm{r}=0.35$ vs 0.34 ). Similar results on adult German population with the same measurement instrument found also other 
researchers (Malesza at al., 2017) hence can be concluded that measurement was conducted with appropriate, high-quality measurement instrument.

\subsection{Data collection}

The measurement i.e. data collection was conducted on two samples:

I) on the Croatian sample of $\mathrm{N}=150$ management students in their second year of studies (on the Course Human Resource Management) at the Faculty of Economics, University of Split in Croatia. From a total of N=150 student subjects, 117 were female and 33 males with age differentiation from 20-29 years. Data collection for this sample was in April and May 2015.

II) on the Slovak sample of N=185 management and economy students (151 on the Course Human Resource Management and 34 on the Course Psychological Training) on the Faculty of Economics, University Matej Bel in Banska Bystrica). In this sample 151 students were the students of third year on the Course Human Resource Management, and 34 students were forth year of study (first year of master level study) with age differentiation from 19-24 years. In this sample 151 were female and 34 male students. Data collection for this sample was in April 2016.

\subsection{Procedure of data collection}

The procedure for two samples (Croatia and Slovakia) was the same. To the students were explained the goals of the research, and they were kindly asked for their approval to be included in this research. Only students who agreed participated in the survey. The questionnaire filling was anonymous and took approximately five minutes. The data processing was conducted in the SPSS statistical package.

\section{Research results and discussion}

To deal with the first research problem, we identified high values of dark triad items in the Croatian \& Slovak sample. The results are presented by the ordered problems (scheduled in the introduction part) i.e.:

A) Identification the items from the Croatian \& Slovak sample that have high values in dark management triad component variables (Machiavellianism, narcissism and subclinical psychopathy) as compared to the Canadian sample.

B) Comparison of the deviant management scales (Machiavellianism, narcissism and subclinical psychopathy) between the Croatian sample $(\mathrm{N}=150)$, Slovak $(\mathrm{N}=185)$ and the Canadian sample $(\mathrm{N}=387)$ from the research of Jones \& Paulhus (2012).

C) Examination of extremely values in targeted variables i.e. examination how much persons have potential harmful Machiavellianism, narcissism and subclinical psychopathy and extremely harmful whole psychological Dark side profile in Croatia \& Slovakia.

D) Examination if there is a statistically significant difference in the variables of Machiavellianism, narcissism and psychopathy between male and female management students, also between students who works during the study with students who do not work during their study, in the Croatian \& Slovakian sample.

Finally, there is given the discussion about possible causes of obtained results on the Croatian \& Slovak sample and are given practical implications for HRM and general organizational management how to deal with dark side's personalities to avoid or diminish their potential future negative effects in organizations. 


\subsection{Results about the first problem}

In purpose to identify the items from the Croatian \& Slovak sample which have high values in target component variables (Machiaveliannism, narcissism and subclinical psychopathy) after the defined criterion, is presented the descriptive statistics (arithmetic means and standard deviations) of each item of the dark triad measures in Table 4, and described in three parts:

I) high value items from the variable Machiavellianism in the Croatian \& Slovak sample;

II) high value items from the variable narcissism in the Croatian \& Slovak sample; and

III) high value items from the variable psychopathy in the Croatian \& Slovak sample.

In the following text, $M$ denotes the mean, while $s$ denotes the standard deviation.

Table 4. Arithmetic means and standard deviations of dark triad items obtained from of the Croatian \& Slovak sample

\begin{tabular}{|c|c|c|c|c|}
\hline $\begin{array}{l}\text { Name of items (Items from No. 1-9 = Machiavellianism; Items from No. 10-18 } \\
=\text { narcissism; Items from No. 19-27 = psychopathy) }\end{array}$ & $\begin{array}{l}\text { Mean } \\
\text { Croatia }\end{array}$ & $\begin{array}{l}\text { Standard } \\
\text { Deviation } \\
\text { Croatia }\end{array}$ & $\begin{array}{l}\text { Mean } \\
\text { Slovakia }\end{array}$ & $\begin{array}{l}\text { Standard } \\
\text { Deviation } \\
\text { Slovakia }\end{array}$ \\
\hline 1. It's not wise to tell your secrets. & 4.220 & .703 & 3.6757 & .80939 \\
\hline 2. Generally speaking, people won't work hard unless they have to. & 3.920 & .773 & 2.9784 & .94958 \\
\hline 3. Whatever it takes, you must get the important people on your side. & 3.580 & .829 & 3.2595 & .93700 \\
\hline 4. Avoid direct conflict with others because they may be useful in the future. & 3.360 & .914 & 3.3189 & .93304 \\
\hline 5. It's wise to keep track of information that you can use against people later. & 2.940 & 1.159 & 2.6432 & 1.06947 \\
\hline 6. You should wait for the right time to get back at people. & 2.900 & 1.349 & 2.6703 & 1.25301 \\
\hline $\begin{array}{l}\text { 7. There are things you should hide from other people because they don't need to } \\
\text { know. }\end{array}$ & 4.260 & .846 & 3.6595 & 1.05177 \\
\hline 8. Make sure your plans benefit you, not others. & 3.560 & 1.172 & 2.9676 & .99947 \\
\hline 9. Most people can be manipulated. & 3.800 & .723 & 3.2324 & .92960 \\
\hline 10. People see me as a natural leader. & 2.960 & .776 & 2.8108 & .81554 \\
\hline 11. I hate being the center of attention. (R) & 3.400 & .897 & 2.9730 & .91742 \\
\hline 12. Many group activities tend to be dull without me. & 2.780 & 1.009 & 2.8216 & .85692 \\
\hline 13. I know that I am special because everyone keeps telling me so. & 2.800 & .919 & 2.7514 & .92831 \\
\hline 14. I like to get acquainted with important people. & 3.500 & 1.008 & 3.6919 & .83222 \\
\hline 15. I feel embarrassed if someone compliments me. (R) & 3.240 & 1.034 & 3.2757 & 1.03457 \\
\hline 16. I have been compared to famous people. & 2.960 & 1.152 & 2.7514 & .99061 \\
\hline 17. I am an average person. (R) & 3.460 & .924 & 3.4108 & .95205 \\
\hline 18. I insist on getting the respect I deserve. & 3.560 & .901 & 3.3189 & .93304 \\
\hline 19. I like to get revenge on authorities. & 2.620 & 1.078 & 1.8486 & .76529 \\
\hline 20. I avoid dangerous situations. (R) & 3.700 & .880 & 2.7081 & 1.03272 \\
\hline 21. Payback needs to be quick and nasty. & 2.400 & 1.080 & 2.1622 & .93581 \\
\hline 22. People often say I'm out of control. & 2.280 & 1.099 & 2.0973 & .87926 \\
\hline 23. It's true that I can be mean to others. & 2.780 & 1.208 & 2.3243 & 1.00147 \\
\hline 24. People who mess with me always regret it. & 2.440 & 1.045 & 1.7297 & .74632 \\
\hline 25. I have never gotten into trouble with the law. (R) & 3.800 & 1.418 & 1.9892 & 1.18408 \\
\hline 26. I like to pick on losers. & 2.040 & 1.284 & 1.6162 & 67466 \\
\hline 27. I'll say anything to get what I want. & 2.640 & 1.216 & 2.0270 & .95230 \\
\hline
\end{tabular}


From the table 3. and according to the defined criterion we have made the identification of critical (high valued) items of the Croatian \& Slovak sample in the parts that have critically i.e. significant higher values in Dark Management Triad as is defined (one standard deviation above the arithmetic mean of basic Canadian sample).

At first glance we observed higher results on the Machiavellianism scale (items 1-9) and there is obvious that every Machiavellian item of Slovakian is lower value than in Croatian sample, but this tell us nothing what is in fact high value in the measured variable. For the criterion (what is significantly/critical higher value) is used the basic Canadian sample treated here as control group/sample (table 1). Because the Canadian sample's mean for the variable Machiavellianism $(M=3.1 ; s=0.76)$ is a result that falls more than one standard deviation below the arithmetic mean of Machiavellianism (greater or equal to $\mathrm{M}=3.86$ ), the values of this item for Croatian and Slovak sample can be considered as high. According to this criterion (one standard deviation above the basic arithmetic mean from the Canadian sample with $\mathrm{N}=387$ measurements), the high Machiavellianism item values of the Croatian sample were:

- $\quad$ 1. "It is not wise to tell your secret" $(M=4.22 ; s=0.70)$;

- 2. "Generally speaking, people won't work hard unless they have to" ( $M=3.92 ; s=0.77)$;

- 7. "There are things you should hide from other people because they don't need to know" $(M=4.26 ; s=0.86)$.

Based on these results, we concluded that from the nine items of the Machiavellianism variable, the Croatian students scored higher in three items. Also, the item 9, "Most people can be manipulated" $(M=3.80 ; s=0.72)$ can be seen as high in the Croatian sample and is somewhat higher than the Machiavellianism mean in the Canadian sample also in Slovak sample $(M=3.23$; $s=0.93)$. In Slovak sample, there is found no Machiavellianism value in any item that is above defined $\mathrm{M}=3.86$ (one standard deviation above arithmetic mean of Canadian sample) so we have clear difference between Croatian and Slovak sample in items 1, 2, 7 already the item 9. These results direct us to the conclusion that Croatian students scored higher in typical Machiavellianism items than Slovak and Canadian students.

As to narcissism (items 10-18), similarly, we consider a result to be significantly higher if it falls more than one standard deviation above the Canadian sample arithmetic mean $(M=2.80 ; s=0.88)$, so a significantly high $M_{\text {Narcissism }}$ should be greater or equal to $\mathrm{M}=3.68$. By this criterion, there are no "significantly" high results in any narcissism item in the Croatian sample, and in Slovak sample one narcissism item (14. "I like to get acquainted with important people") was high according settled criterion $(\mathrm{M}=3.69 ; \mathrm{s}=0.83)$. Higher Slovak result in this item shows the perceived importance of himself in the terms of important people-so in this way Slovak students may be perceived more narcissism prone.

According to the same criterion, concerning the dark triad component scale of psychopathy (items 19-27), the Canadian sample scores $M=2.4 ; \mathrm{s}=1.00$, so significantly higher results in the Croatian sample should be the items where $M_{\text {psychopathy }}$ is greater or equal to $\mathrm{M}=3.40$. Such psychopathy items in Croatian sample were:

- 20. "I avoid dangerous situations" (R) $(M=3.70 ; s=0.88)$ - this means a question about liking dangerous situation (because this is a reversed item).

- 25. "I have never gotten into trouble with the law" (R) $(M=3.80 ; s=1.42)$ - this means a question about having troubles with the law (because it is a reversed item).

Of the nine items describing psychopathy, two items of the Croatian sample scored higher. In Slovak sample, there was no one item which was at high value according the mentioned criterion $(\mathrm{M}=>3.40)$. This is also interesting results and direct us the sources of differences in this two samples (Slovak and Croatian). 


\subsection{Results about the second research problem (Comparison between the Dark Triad components between the Croatian and Slovakian sample)}

The results of the comparison of the deviant management scales (Machiavellianism, narcissism and psychopathy) between the Croatian sample ( $=150)$, Slovak $(\mathrm{N}=185)$ are presented in the Table 5.

Table 5. Arithmetic means and standard deviations for the variables (scales) Machiavellianism, narcissism, and psychopathy on the Croatian and Slovak sample

\begin{tabular}{|c|c|c|c|c|}
\hline \multirow{2}{*}{} & \multicolumn{2}{|c|}{ CROATIAN SAMPLE N=150 } & \multicolumn{2}{c|}{ SLOVAK SAMPLE N=185 } \\
\cline { 2 - 5 } & Mean & Stand. Dev. & Mean & 0.468 \\
\hline Machiavellianism & 3.615 & 0.536 & 3.156 & 0.491 \\
\hline Narcissism & 3.184 & 0.455 & 3.090 & 0.495 \\
\hline Psychopathy & 2.744 & 0.592 & 2.056 & Dev \\
\hline
\end{tabular}

Source: Research results

To determine whether the results on the scales of Machiavellianism, narcissism and psychopathy are statistically significantly different between the Croatian, and Slovakian samples (from descriptive results in table 4.), we conducted a simple t-tests. The results can be summarized as follows:

a) The Croatian sample has statistically significant higher Machiavellianism than the Slovak sample $(t=8.36$; $\mathrm{df}=333 ; p<0.01)$. It is interesting to note, that the comparison in Machiavellianism variable between Canadian (table 1.) and Slovak sample was statistically insignificant $\mathrm{t}=0.92 ; \mathrm{df}=570 ; \mathrm{p}>0.05$; and between Canadian and Croatian sample statistically significant $\mathrm{t}=7.60 ; \mathrm{df}=535 ; \mathrm{p}<0,01$. This shows us that Machiavellianism variable values are similar between Canadian and Slovak students, and Croats shows significant higher Machiavellianism.

b) The Croatian sample has not statistically significant higher narcissism than the Slovak sample, i.e. there was no statistically significant difference $(t=1.80 ; \mathrm{df}=333 ; p>0.05)$. We can note, that the comparison in narcissism variable between Canadian (table 1.) and Slovak sample was statistically significant $\mathrm{t}=4.18$; $\mathrm{df}=570 ; \mathrm{p}<0.01$; and between Canadian and Croatian sample also statistically significant $\mathrm{t}=5.09$; $\mathrm{df}=535$; $\mathrm{p}<0.01$. So it is to conclude that Croats and Slovaks are significantly higher in narcissism, what can be atributed to the different cultural values.

c) The Croatian sample had statistically significant higher psychopathy than the Slovak sample $(t=11.58$; $\mathrm{df}=333 ; p<0.01$ ). Also comparison in psychopathy variable between Canadian (table 1.) and Slovak sample was statistically significant $\mathrm{t}=4.42 ; \mathrm{df}=570 ; \mathrm{p}<0.01$ but in the opposite direction i.e. higher was psychopathy in Canadian sample than in Slovak sample; and between Canadian and Croatian sample also statistically significant $\mathrm{t}=3.95 ; \mathrm{df}=535 ; \mathrm{p}<0,01$ (higher psychopaty in Croatian sample). Here is to conclude that the psychopathy variable is significantly higher in Croatia in both comparisons (Slovakia and Canada), and significantly higher in Canada than in Slovakia. Slovak sample shows here the lowest psychpathy level.

Higher result on Machiavellianism suggest the tendency of exploiting the others and the direction exclusively on himself (Jakobowitz \& Egan, 2006). It should be noted that there are several cultural-social determinants of the Croatian sample population which are possible mediators of such results. Manipulative strategies in interpersonal relationships, seeing others as week and liable to influence and the irreverence traditional moral norms (Corral \& Calvete, 2000), can be explained by cultural change. For example, a statistically significant high result in a Machiavellianism variable can be explained in terms of increased competition because of the situation of higher and long-term unemployment in Croatia, where economics \& management students perceive that the ends are more important than the means, so if they want to succeed, they should behave in a Machiavellianism manner. A possible explanation of the emphasized Machiavellianism values in the Croatian sample is that such behaviors are 
rewarded (Pastuović, 1999) and is clear perceived, that in Croatian society successful people have dominant Machiavellianism personal traits. It should be noted that in Croatia, honesty, justice, integrity and altruism are rarely rewarded in terms of social success. Also, parents and the external environment of examined Croatian students may not internalize in their pedagogy the value model of integrity, truth, love, correct behavior, equanimity, nonviolence, integrity (ethical values), but rather the values of "you should adapt to the current situation”.

Also, these days, some Croats are rarely shocked by non-ethical and criminal behavior if they result in material wealth and social prestige. In everyday small talks, it can be heard that some Croatian people would like to have the benefits which come from unethical or even criminal ways, if only they had a chance to do it. This can be illustrated by the fact that one of the former Croatian ministers of finance stated "I would steal under certain conditions!" (http://www.republika.eu/novost/22552/krao-bih-pod-odredenim-uvjetima-ne-sramim-se-toga - „I would steal under some condition, I do not feel shame about this"). The justice system in Croatia does not function very well, and social success is measured by how much common property (social property from the former socio-economic formation) is privatized. The culture in Croatia favors fast wealth making, and Machiavellianism is a good tool to achieve that. So in a culture where the counter-normal Machiavellianism behavior is normalized, it is obvious that the Croatian sample displays somewhat higher Machiavellian values.

Even the Slovaks tends to higher Machiavellianism. It is a result of cultural and ethical transformation of the former totalitarian country into democratic. The early capitalism period in Slovakia (1989-2000) was marked by symptoms of Machiavellianism - the dark and grey economy due to business environment establishment, new phenomenon in national economy - unemployement and relating social issues. Nowadays, the situation in Slovakia is more standard, government is taking actions to reduce corruptions and law enforcement. New rules and values based on fairness and ethic appears in Manifesto of the Government. The Machiavellianism indicators in Slovakia reached the highest values in 1995-2000. New economic and political culture is giving a chance for Machiavellianism reduction in the future.

There was found no statistically significant higher narcissism of Croatian students in comparison with Slovaks, so in these characteristics the samples are similar, although they are higher in comparison with Canadian student sample $(\mathrm{M}=2.8 ; \mathrm{s}=0.88)$. Also, the statistically significant higher narcissism of Croatian and Slovak students can be attributed to the genetic (Gattaz, 1981 according Pastuović, 1999, p. 223) and social factors characteristics of this sample. In this work, however, we discuss only the social factors. Narcissism and the feeling of some Croatian people that they are better than others may be internalized by parents' pedagogy, and it can also be the consequence of a national narcissism legend that Croats are more capable, smarter, more beautiful, and stronger (e.g. in sport) than other nations. Narcissism could relate to a defensive mechanism in the situation when the desired goals are not achieved.

Psychologically and culturally Croats are likely to be successful, smart and rich, and the easiest way to achieve it is preferred; i.e. if it is easier to achieve it via narcissism's rationalization approach, then it would be more likely to be used in the population. According to Landes (2003), pride, self-contentment, the paradox of a superiority complex, disdain and underestimation, lack of clarity and manipulation, i.e. narcissistic behaviors, are connected with the culture of economic stagnation, so such statistically significantly higher personality traits in the Croatian sample can be a result of the long-term stagnation of Croatian enterprises and economy.

The Slovak sample higher narcissism can be attributed to the similar explanation as in Croatian. It is a question of historical culture of totalitarian regime. Private property and free market restrictions, full employment, central economy planning and decision making. All these phenomenon leaded within 40 years to empathy reduction, subjection and self confidence disruption. The period after Velvet Revolution in 1989, typical by freedom, 
released emotional potential of Slovaks. New children upbringing patterns based on economical diversion of society, throwing up the traditional values reflected to narcissism of young generation. In a lot of cases we can talk about arrogant narcissistic disorder of young generation. This subtype of narcissism is perceived as by dumping and the surrounding others perceived as hurtful and arrogant, or on the other hand, as a charismatic leader.

Statistically significantly higher subclinical psychopathy of the Croatian sample can be explained by the combination of genetic and social factors of this sample, and can be partially attributed to the higher Machiavellianism and narcissism, because the concepts of the dark triad are not totally pure and they are somehow overlapping (see picture 1. and table 2.). The great deal of psychopathy has genetic reasons (Pastuović, 1999), which are not discussed in this work. A possible genetic marker of psychopathy is HLA-B27 (Gattaz, 1981, according to Pastuović, 1999., p. 223).

Men have statistically higher average results on the psychoticism scale, which indicates a hormonal basis of psychopathy. Other comparative research on kin and non-kin demonstrates a high degree of congenital and inheritance of psychopathy. Psychopaths have difficultly to learn values, and also have a genetic predisposition for antisocial behavior. Psychopaths have a congenital need for strong stimulii, and the best way to satisfy it is by making damage to other persons (Pastuović, 1999, p. 223).

\subsection{Results about the third research problem}

The results of examination of how much persons (examinees have potential harmful Machiavellianism, narcissism and psychopathy and extremely harmful whole psychological Dark side profile in Croatia \& Slovakia is presented in the table 6.

Table 6. Incidence of researched variables in two samples Croatia and Slovakia

\begin{tabular}{|l|l|l|l|l|l|l|}
\hline & \multicolumn{3}{|c|}{ CROATIA } & \multicolumn{3}{c|}{ SLOVAKIA } \\
\cline { 2 - 7 } & Man: N/\% & Women: N/\% & Total: N/\% & Man: N/\% & Women: N/\% & Total: N/\% \\
\hline $\begin{array}{l}\text { Machiavellianism } \\
\text { M>3,86 }\end{array}$ & $23 / 70 \%$ & $37 / 32 \%$ & $60 / 40 \%$ & $8 / 24 \%$ & $7 / 5 \%$ & $15 / 8 \%$ \\
\hline $\begin{array}{l}\text { Narcissism } \\
\text { M>3,68 }\end{array}$ & $3 / 9 \%$ & $9 / 8 \%$ & $12 / 8 \%$ & $2 / 6 \%$ & $11 / 7 \%$ & $13 / 7 \%$ \\
\hline $\begin{array}{l}\text { Psychopathy } \\
\text { M>3,40 }\end{array}$ & $7 / 21 \%$ & $9 / 8 \%$ & $16 / 11 \%$ & $2 / 6 \%$ & $0 / 0 \%$ & $2 / 1 \%$ \\
\hline Dark Triad & $3 / 9 \%$ & $3 / 3 \%$ & $6 / 4 \%$ & $1 / 3 \%$ & $0 / 0 \%$ & $1 / 0.5 \%$ \\
\hline
\end{tabular}

Source: Research results

From the table 6. can be seen the interesting result in Machiavellianism, i.e. that already $40 \%(60 / 150)$ of the Croatian sample was high in Machiavellianism, what is much more than in Slovak sample, i.e. 8\% (15/185). Also, regarding this variable by the gender in the Croatian sample were already $70 \%$ (23/33) males high on Machiavellianism in comparison with 24\% (8/34) in Slovak sample. The same domination of Machiavellianism of Croatian sample is present by women, i.e. 32\% (37/117) by Croats and 5\% (7/151) by the Slovaks respectively. So, it can be seen the clear domination of Machiavellianism in Croatian sample in comparison with Slovak sample. The explanation of such a situation can be the same as it is discussed in the part 3.2. In the narcissism variable, there are not such differences namely it is identified $8 \%(12 / 117)$ by Croats and 7\% (13/151) by the Slovaks, and similar situation is present by the gender. Namely, higher narcissism showed 9\% (7/33) of Croats and $6 \%(2 / 34)$ of Slovak males, and by women this was $8 \%(9 / 117)$ by Croats and $7 \%(11 / 151)$ by Slovaks respectively. 
But in the variable of psychopathy there is obvious difference between the samples of Croatia and Slovakia. Namely $11 \%(16 / 150)$ of Croats and only $1 \%(2 / 185)$ of Slovaks have higher psychopathy values. As is known that to the psychopathy are more prone males (Pastuović, 1999) this were so also in this research, i.e. $21 \%$ of male Croats and $6 \%$ of male Slovaks were high in psychopathy and only $8 \%$ of Croat women and $0 \%$ of Slovak women were high in this variable. The possible explanation of such high result in psychopathy variable by male Croats (very similar as males in penalty institutions where according Black are 15-25\%), but also not low by the women $(8 \%)$ stems perhaps from genetic origin and selection process (namely possible negative selection through longer period, where the best HR was going out of the Croatia are represented in such sample characteristics). Namely it is known the phenomenon that most successful people in some poor societies can be the champions in negative selection (psychopathic and Machiavellianism very prone people), what can be represented in the sample of Croat students.To see what is the frequency of Dark Triad (all three variable components higher value) in this sample we made also this analysis. Although there are little data about this frequency in the literature we can find different data in corporate world (mentioned are between 1 and 5\%). This research showed that in Croatian sample were totally $4 \%(6 / 150)$, i.e. $9 \%$ (3/33) males, and 3\% (3/117) of women, and in Slovak sample totally $0.5 \%(1 / 185), 3 \%(1 / 34)$ of Slovak male and $0 \%$ of Slovak women, extremely dangerous Dark Triad personality (all the components were significantly high). According to these results, it can be concluded that Croatian organizations will potentially have more problems with Dark Triad personalities/individuals than the Slovak organizations. But on larger numbers this problem is not an infrequent one, because also with $0.5 \%$ of such "toxic" dark triad persons in Slovakian population, in the population 10.000 e.g. managers we will have 50 such toxic persons (possibly top managers or politicians which if are also very intelligent can be very dangerous), in Croatia even more. So, this can be quite a serious organizational problem which can potentially destroy organizational and economic development.

\subsection{Results about the forth problem: Difference in the variables of Machiavellianism, narcissism and psychopathy between male and female management students in the Croatian and Slovak Sample}

To explore if there is a statistically significant difference between research variables between female and male subjects in the Croatian and Slovak sample, we performed an ANOVA test. This ANOVA tests were conducted in two parts - Croatian Sample and Slovak Sample. The results of Croatian sample (gender x components of Dark Triad variables) results are presented in table 7.

Table 7. Differences in the variables Machiavellianism, narcissism and psychopathy between male and female students in Croatian sample

\begin{tabular}{|c|c|c|c|c|c|c|}
\hline & & Sum of Squares & df & Mean Square & $\mathrm{F}$ & Sig. \\
\hline MACHIAVELLIANISM & $\begin{array}{l}\text { Between Groups } \\
\text { Within Groups } \\
\text { Total }\end{array}$ & $\begin{array}{l}2.499 \\
40.332 \\
42.830\end{array}$ & $\begin{array}{l}1 \\
148 \\
149\end{array}$ & $\begin{array}{l}2.499 \\
.273\end{array}$ & 9.170 & .003 \\
\hline NARCISSISM & $\begin{array}{l}\text { Between Groups } \\
\text { Within Groups } \\
\text { Total }\end{array}$ & $\begin{array}{l}.142 \\
30.718 \\
30.860 \\
\end{array}$ & $\begin{array}{l}1 \\
148 \\
149\end{array}$ & $\begin{array}{l}.142 \\
.208\end{array}$ & .685 & .409 \\
\hline PSYCHOPATHY & $\begin{array}{l}\text { Between Groups } \\
\text { Within Groups } \\
\text { Total }\end{array}$ & $\begin{array}{l}3.457 \\
48.858 \\
52.315\end{array}$ & $\begin{array}{l}1 \\
148 \\
149\end{array}$ & $\begin{array}{l}3.457 \\
.330\end{array}$ & 10.473 & .001 \\
\hline
\end{tabular}

Source: Research results 
The results suggest that there is a statistically significant difference between male and female Croat subjects $(F=9.171 ; p=0.003)$ in the Machiavellianism variable, and in the psychopathy variable $(F=10.743 ; p=0.001)$. No statistically significant difference was found in the variable of narcissism $(F=0.685 ; p>0,05)$.

Male Croat students scored statistically significantly higher in Machiavellianism $\left(M_{\text {Machiavellianism }}=3.84 ; s=0.47\right)$ as compared to female students $\left(M_{\text {Machiavellianism }}=3.54 ; s=0.54\right)$. Male Croat students also scored statistically significantly higher in psychopathy $\left(M_{\text {psychopathy }}=3.03 ; s=0.61\right)$ when compared to females $\left(M_{\text {psychopathy }}=2.66\right.$; $s=0.56$ ). Such results are consistent with past literature (Furnham et al., 2013), which suggest that male is prone to Machiavellianism and psychopathological behavior.

The results of Slovak sample (gender x components of Dark Triad variables) are presented in table 8.

Table 8. Differences in the variables Machiavellianism, narcissism and psychopathy between male and female students in Slovak sample (ANOVA)

\begin{tabular}{|ll|r|r|r|r|r|}
\hline & & Sum of Squares & df & Mean Square & F & Sig. \\
\hline Machiavellianism & Between Groups & 3.231 & 1 & 3.231 & 15.947 & .000 \\
& Within Groups & 37.073 & 183 & .203 & \\
& Total & 40.304 & 184 & & \\
\hline Narcissism & Between Groups & .167 & 1 & .167 & .693 \\
& Within Groups & 44.141 & 183 & .241 & \\
& Total & 44.309 & 184 & .406 \\
& Between Groups & 3.596 & 1 & 3.596 & 15.869 & \\
\hline Psychopathy & Within Groups & 41.469 & 183 & .227 & .000 \\
& Total & 45.065 & 184 & & \\
& & & & \\
\end{tabular}

Source: Research results

From the table 8 . we can see the same situation by Slovak sample as by the Croatian sample. Namely, the results suggest that there is a statistically significant difference between male and female Slovak subjects $(F=15.947$; $p=0.000)$ in the Machiavellianism variable, and in the psychopathy variable $(F=15.869 ; p=0.000)$. No statistically significant difference was found in the variable of narcissism when compared male and female Slovaks $(F=0.693$; $p>0.05)$. The conclusion about this results is the same as by Croatian sample.

In the comparison of dark triad variables and criterion of working during the study no one significant difference was found in Croatian sample. In Slovak sample, only by psychopathy $(\mathrm{F}=15.87$; $\mathrm{p}<0.01)$ in the direction of somewhat higher value on psychopathy by the examinees which not work during the study (M=2.18) in comparison with examinees who work during their study $(\mathrm{M}=1.95)$. But this arithmetical means are so low that cannot be conclusive, and this cannot be significant/important because in the variable of psychopathy in Slovak sample are only two higher values so cannot be generalized on the sample.

\section{Measures for reducing the dark triad organizational threat}

While the Croatian sample had statistically significant higher dark triad values than the Canadian sample, it is clear that no one organization is immune to dark triad and its component effects. In HRM are visible the obstacles 
with the employees which has dark side characteristics. So, it is important to find ways to reduce and avoid the dark side's effects in organizations. The basic approach could involve:

\section{(I) Preventive measures:}

a) Improvement the HRM practice: in the employment process (recruitment and selection), professional selection the employees for some specific jobs, advancement and transfer. When some candidates lack concern over ethics, it indicates a manipulative personality (Machiavellianism). When some candidates are over-confident, over-selfpromoting or entitled, this is an indication of a narcissistic personality, and if some of candidates overuse the impression management tactics it can be an indication of a psychopathic personality. So, it is to expect that dark triad individuals will try during the selection process to make the impression of the most acceptable candidates, but his real "face" they will show much later. Also, it is to know that intelligent persons with dark triad can also manipulate with test material, and in every phase of selection process (it shows that extremely inteligent and manipulative are extremely dangerous). For that purpose Babiak \& Hare (according Langbert, 2010) propose structural behavioral interviews before introducing the employees in the organization. Although there is no universal suggestion it is important to in HR diagnosis to identify which candidates are those and which characteristic are high (Spain, Harms \& Lebreton, 2013). Namely, bad can be managerial decision to engage the team with peoples prone to subclinical psychopathy. Therefore, is especially important to educate the HRM staff to recognize some of discrete malign phenomena and behaviors in order to prevent the possible negative impacts of dark triad personalities.

b) Improvement the workplace conditions: The organizational conditions that may "bring out" the dark triad in current employees include e.g. "pitting" of teams or departments against each other, unequal treatment, lack of structure, misunderstood corporate values, deliberate management manipulation. In improved psychosocial workplace conditions there is less chance to have dark-triad persons in charge and organizational suffering from their operations.

c) Ethics education and promotion of spirituality management. Introducing servant leadership with human values of truth, doing right, love, peace and nonviolence promotes an ethical organizational climate/culture. With such a socialization, dark triad behaviors can be in some extent prevented.

\section{(II) Reactive measures:}

a) Raising management awareness and dealing with Dark Triad individuals. Stimulating the thinking of managers around the potential of the "dark triad" personalities of engaged human resources in organization to improve organizational shortcomings or even crisis (e.g. disturbed human relationships, job dissatisfaction, poor job engagement/motivation, poor job performances). This is important to make responsive actions to effectively manage them (when the preventive measures missed to recognize the dark triad persons). For example, in the case of complaint on behavior of some employees it can be used the check list which can use educated HRM staff (professional) who is skilled in recognizing specific behaviors. Because Dark triad persons communicate and behave on very different way with different persons (on one way with superiors and totally different way with subordinates sometimes it is difficult to sign such employees (Boddy, 2005). The reactive measure is also important because the change of dark side characteristics is also possible by means of organizational interventions (Hogan, Curphy \& Hogan 1994 according Spain, Harms \& Lebreton, 2013). The managerial awareness about dark triad problem is crucial for reaction on it.

b) Raising employee awareness and dealing with Dark Triad individuals. When the threat of dark triad persons in organization is obvious and very real, employees should not confide things (either in oral or written form) or trust without verifying; they should be careful of charming smiles, and be alarmed by unethical behavior or violent behavior from higher management or board of an organization. Here also can help specific informing and trainings which give the knowledge about the ways, characteristics and harmful activities of "toxic" employees (Langbert, 2010). Anonym lines where employees can register unappropriated/nonprofessional behaviors to identify such individuals can be helpful. In the frame of HRM working condition and health protection it is also 
important to assure the support to the employees who are the victims of dark triad individuals or even groups (cf. Bogdanović, Durian \& Cingula, 2016).

In general, to affront with organizational dark triad characteristic it is of crucial importance the organizational communication. Open, unambiguous and effective communication lower the psychological space for manipulation behaviors. If the organizational politics to the employees is clear, consistent, directed to the tasks and goals execution, to the quality of human relationships, if the organization is in effort to raise the awareness of management and employees and dealing with the problems in general, so is enhanced the possibility of limiting the employees with dark side characteristics in their activity (Baboselac-Marić, 2015). Honesty, culture of correct behavior and truth is very important as preventive and reactive measure in dealing with dark triad individuals.

\section{Limitations and proposals for further research}

The main limitation of the conducted research is a limited sample with a relatively low number of subjects in two samples $(\mathrm{N}=150$ in Croatia and $\mathrm{N}=185$ in Slovakia), which was also conducted at only one Croatian and one Slovak University. Another limitation can be the language differences between the English and Croatian/Slovak versions of the questionnaires, although the translation was conducted in "the spirit of language" (e.g. item 5 was translated as "It's true that I can be evil to others" because the language can represent different social norms). Also e.g. the term "losers" has a different denotative meaning in "Anglo-Saxon" society and culture than in e.g. Croatian/Slovak culture (in former Yugoslavia/Czechoslovakia under socialism, such a term was practically unknown and thus it still does not have such a negative connotation in Croatia/Slovakia as it has elsewhere; rather, it means something closer to be unlucky). The language differences could make small differences in the results. For these reasons, in high-quality psychometric research, there is a need to standardize questionnaires that are supposed to be valid in a specific cultural surrounding. Another limitation is the comparison with the Canadian sample, which is a totally different culture than the Croatian/Slovak one. Therefore, for Croatian and Slovak norms for subclinical Machiavellianism, narcissism and psychopathy to be obtained, this research should be done on a larger sample. We suggest that further research on the dark management triad should be conducted in other Croatian and Slovak regions, so different results in dark triad traits can be expected. Croatia consist of five different geographic regions which are culturally and mentality somewhat different (Ozimec, 2001) and similar is in Slovakia. Slovakia consists of three different regions; different by geography, by mentality and by conditions for further development. The research of the dark management triad in transition economies and organizations is in a very early phase (organizational treatment by HRM or company management also). There is quite a large space for further research in this management and organization area in other countries.

For example, the research of dark management triad in the countries which resulted from the former Yugoslavia (Slovenia, Croatia, Bosnia and Herzegovina, Serbia, Montenegro, Kosovo and Macedonia) or in other transition economies (Slovakia, Check Republic, Hungary, Romania, Bulgaria, Ukraine, Poland, Latvia, Lituania, Letonia) could be promising.

To understand the deviant workplace behavior of dark triad personalities more completely, there is need to apply a multi-paradigmatic approach, e.g. the Burell \& Morgan's framework (Samnani, 2013). For a deeper understanding of the deviant workplace behavior, the following approaches can be applied:

a) Functionalist approach - where the emphasis is on predicting which interpersonal characteristic contributes to the deviant organizational situation, i.e. discovering of regularities and causal relationships that exist between the variables of interest.

b) Interpretivism approach - which emphasizes understanding of employees' feeling and meanings about toxic employees and deviant workplace/organizational situations.

c) Critical management theory approach - which emphasizes the role of power and alienation in institutions, i.e. the focus of research is on broader issues of power within institutions, which may be stimulus for 
workplace/organization deviations. Deviant workplace/organizational situations can be researched as the result of authority and discipline which normalizes such a situation in the eyes of society and the employees.

d) Post-modernistic perspective - emphasizes the presence of multiple "truths", need for emancipation and wellbeing of employees and the focus of research is on the management practices that produce organizational obedience through the simple exertion of power, control and surveillance. Post-modernistic research is focused less on performance enhancement but more on emancipation and well-being of employees.

Therefore, seeking to understand the deviant workplace/organizational situation in terms of dark side personalities could include multi-paradigmatic approaches of organizational research.

\section{Conclusion}

This research has the following main findings:

- Machiavellianism and subclinical psychopathy was higher in Croatian than Slovak sample (statistically significant and $\mathrm{p}<0.01$ level). In the narcissism variable, there were not significant difference $(\mathrm{p}>0.05)$.

- More Machiavellian, subclinical psychopathic and "dark triad" personalities is found in Croatian sample than in Slovak sample. In Croatian sample, it is found $4 \%$ of dark triad personalities and $0.5 \%$ in Slovak sample. But also in Slovak sample although in some lower level than in Croatian sample is identified the dark triad presence.

- In the both of Croatian and Slovak sample, we found statistically significant differences between male and female subjects in Machiavellianism and psychopathy $(\mathrm{p}<0.01)$, in the direction of higher values of male students, but not in the scale of narcissism ( $p>0.05)$.

- The cause of statistically significant higher results of dark triad variables in the Croatian sample in comparison with the Slovak sample can be explained by cultural and social determinants of the examined populations.

For dealing with the challenge of Dark Triad personalities proposed are the practical implications for organization and management in two senses:

I) Preventive measures:

a) Improvement the HRM practice: in the employment process (recruitment and selection), selection the employees for some specific jobs, advancement and transfer. When some candidates lack concern over ethics, it indicates a manipulative personality (Machiavellianism). When some candidates are over-confident, over-selfpromoting or entitled, this is an indication of a narcissistic personality, and if some of candidates overuse the impression management tactics it can be an indication of a psychopathic personality. In HR diagnosis is especially important to educate the HRM staff to recognize some of discrete malign phenomena and behaviors to prevent the possible negative impacts. Implementation of multiple feedback on manager's competences into HRM processes of HR diagnosis. Feedback based on working behavior observation identify Dark Triad symptoms and leads to working with the feedback.

b) Improvement the workplace conditions: The organizational conditions that may "bring out" the dark triad in current employees include e.g. "pitting" of teams or departments against each other, unequal treatment, lack of structure, understood corporate values, deliberate management manipulation. Clear organizational communication and management example which communicate inappropriateness of dark triad behaviors here is crucial.

c) Ethics education and promotion of spirituality management. Introducing servant leadership with human values of truth, doing right, love, peace and nonviolence promotes an ethical organizational climate/culture. The dark triad behaviors can be to a certain extent prevented with such a organizational socialization.

II) Reactive measures:

a) Raising management awareness and dealing with Dark Triad individuals. Stimulating the thinking of managers around the potential of the "dark triad" personalities of engaged human resources in organization to avoid 
The International Journal

ENTREPRENEURSHIP AND SUSTAINABILITY ISSUES

ISSN 2345-0282 (online) http://jssidoi.org/jesi/

2018 Volume 5 Number 4 (June)

http://doi.org/10.9770/jesi.2018.5.4(19)

organizational shortcomings or even crisis (e.g. disturbed human relationships, job dissatisfaction, poor job engagement/motivation, poor job performances). This is important to make responsive actions to effectively manage them (when the preventive measures missed to recognize the dark triad persons and avoid their organizational engagement).

b) Raising employee awareness and dealing with Dark Triad individuals. When the threat of dark triad persons (e.g. some individual, manager or even employer) in organization is obvious and very real, employees should not confide things (either in oral or written form) or trust without verifying; they should be careful of charming smiles, and be alarmed by unethical behavior or violent behavior from higher management or board of an organization.

Dark triad persons can be very dangerous (especially if they are managers/business leaders), because in their organizational presence, a favorable ethical climate and culture is not possible. Therefore, organizations have every responsibility to avoid dark triad negative effects. This avoidance can be operationalized by preventive and responsive actions to manage the "toxic employees" threat.

\section{References}

Arvan, M. (2011). Bad news for conservatives: Moral judgments and the Dark Triad personality traits: A correlational study. Neuroethics. https://doi.org/10.1007/s12152-011-9140-6

Baboselac-Marić, M. (2015). Zaposlenici “otrovnih” karakteristika i njihov utjecaj na organizaciju: Jesu li zločesti ili su zli? [Employee's with "toxic" characterstics and their impact on organization: Are they roguish or evil?] Policija i sigurnost, Zagreb, 24(3): 261-273. Accessed 20 June 2018. Available at: https://hrcak.srce.hr/index.php?show=clanak\&id_clanak_jezik=231449

Barrick, M.R., \& Mount, M.K. (1991). The Big Five personality dimensions and job performance: A meta-analysis. Personnel Psychology, 44(1): 1-26. https://doi.org/10.1111/j.1744-6570.1991.tb00688.x

Baughman, H.M., Dearing, S., Giammarco, E., \& Vernon, P.A. (2011). Relationships between bullying behaviours and the Dark Triad. Personality and Individual Differences, 52: 571-575. https://doi.org/10.1016/j.paid.2011.11.020

Black, P. J. (2013). The Dark Triad and interpersonal assessment of vulnerability: Cues used and accuracy. Master thesis. Faculty of graduate study in Psychology University of British Columbia. Available at: https://open.library.ubc.ca/cIRcle/collections/ubctheses/24/items/1.0073544

Boddy, C.R. (2005). The Implications of Corporate Psychopaths for Business and Society. An initial examination and a call to arms, Australasian Journal of Business and Behavioural Sciences (AJBBS) 1(2), 30-40. Accessed 20 June $2018 . \quad$ Available at: http://www.stempeldrang.nl/uploads/4/8/5/5/4855530/psychopath.pdf

Boddy, C.R. (2011). Corporate Psychopaths, bullying and unfair supervision in the workplace. Journal of Business Ethics, 100: $367-379$. https://doi.org/10.1007/s10551-010-0689-5

Boddy, C.R. (2015). Psychopathic Leadership: A Case Study of a Corporate Psychopath CEO. Article published with open access at Springerlink.com. https://doi.org/10.1007/s10551-015-2908-6; published later in Journal of Business Ethics (2017), 145(1): 141-156. https://doi.org/10.1007/s10551-015-2908-6

Bogdanović, M. (2016). Contribution to the Theories of Working Motivation/Job Engagement: Human Mind Manipulation as Managerial Motivation Tool, Proceedings of Scientific Papers from the 13th International Scientific Conference Human Potential Development, Szczecin, Poland, 07-09 June 2016, p. 27-43. ISBN: 978-83-7518-782-3.

Bogdanović, M., Durian, J., Cingula, D. (2016). HRM Choices for Business Strategy Support: How to Resolve the Most Important Dilemmas? Book of Proceedings 15th International Scientific Conference on Economic and Social Development - Human Resources Development, Varaždin, Croatia 09-10 June 2016., p. 429-445. ISSN: 1849-7535.

Bradlee, P. M., \& Emmons, R. A. (1992). Locating narcissism within the interpersonal circumplex and the Five-Factor model. Personality and Individual Differences, 13: 821- 830. http://dx.doi.org/10.1016/0191-8869(92)90056-U 
The International Journal

ENTREPRENEURSHIP AND SUSTAINABILITY ISSUES

ISSN 2345-0282 (online) http://jssidoi.org/jesi/

2018 Volume 5 Number 4 (June)

http://doi.org/10.9770/jesi.2018.5.4(19)

Chabrol, H., van Leeuwen, N., Rodgers, R., \& Séjourné, N. (2009). Contributions of psychopathic, narcissistic, Machiavellian, and sadistic personality traits to juvenile delinquency. Personality and Individual Differences, 47: 734-739. http://dx.doi.org/10.1016/i.paid.2009.06.020

Chopra, R.A. (2013). Narcissist, a Psychopath and a Machiavellian Walk into a Bar. Accessed 20 June 2018. Available at: https://psychometricsforumblog.wordpress.com/2013/06/23/a-narcissist-a-psychopath-and-a-machiavellian-walk-into-a-bar/

Christie, R., Geis, F. (1970). Studies in Machiavellianism. New York, NY: Academic Press. ISBN: 978-0-12-174450-2.

Corral, S., Calvete, E. (2000). Machiavellianism: Dimensionality of the Mach IV and its relation to self-monitoring in a Spanish sample. The Spanish Journal of Psychology, 3(1), 3-13. pmid: 11761738, https://doi.org/10.1017/S1138741600005497 Published online: 01 April 2014.

Dahling, J. J., Whitaker, B. G., Levy, P. E. (2009). The Development and Validation of a New Machiavellianism Scale. Journal of Management, 35: 219-257. https://doi.org/10.1177/0149206308318618

Einarsen, S., Aasland, M. S., \& Skogstad, A. (2007). Destructive leadership behaviour: A definition and conceptual model. The Leadership Quarterly, 18: 207-216. http://dx.doi.org/10.1016/j.leaqua.2007.03.002

Fischbacher-Smith, D. (2015). The enemy has passed through the gate: Insider threats, the dark triad, and challenges around security. Journal of Organizational Effectiveness: People and Performance, 2(2): 134-156. Emerald Group Publishing Limited 2051-6614. https://doi.org/10.1108/JOEPP-03-2015-0010

Furnham, A. (2010). The Elephant in Boardroom: The Causes of Leadership Derailment. Basingstoke: Palgrave MacMillan. https://doi.org/10.1057/9780230281226 Hardcover ISBN: 978-0-230-22953-2.

Furnham, A., Richards, R. C, Paulhus D. L. (2013). The Dark Triad of Personality: A 10 Year Review. In: Social and Personality Psychology Compass. Blackwell Publishing Company, 7(3) 199-216. https://doi.org/10.1111/spc3.12018

Gosling, S. D., Rentfrow, P.J., Swan, W. B. Jr. (2003). A Very Brief Measure of the Big Five Personality Domains. Journal of Research in Personality, 37: 504-528. https://doi.org/10.1016/S0092-6566(03)00046-1

Gustafson, S.B., \& Ritzer, D.R. (1995). The dark side of normal: A psychopathy-linked pattern called aberrant self-promotion. European Journal of Personality, 9(3): 147-183. https://doi.org/10.1002/per.2410090302

Jakobowitz, S., Egan, V. (2006). The dark triad and normal personality traits. Personality and Individual Differences. 40: 331-339. https://doi.org/10.1016/j.paid.2005.07.006

Jonason, P. K., Krause, L. (2013). The emotional deficits associated with the Dark Triad taits: Cognitive empathy, affective empathy, and alexithymia. Personality and Individual Differences, 55(5): 532-537. http://dx.doi.org/10.1016/j.paid.2013.04.027

Jonason, P. K., Slomski, S., Partyka, J. (2012). The Dark Triad at work: How toxic employees get their way. Personality and Individual Differences, 52: 449-453. http://dx.doi.org/10.1016/j.paid.2011.11.008

Jonason, P. K., Webster, G. (2010). The Dirty Dozen: A Concise Measure of the Dark Triad. Psychological Assessment, 22(2): 420-432. http://dx.doi.org/10.1037/a0019265

Jonason, P. K., Wee, S., Li N. P. (2015). Competition, autonomy, and prestige: Mechanisms through which the Dark Triad predict job satisfaction, Personality and Individual Differences, 72: 112-116. http://dx.doi.org/10.1016/j.paid.2014.08.026

Jones, D. N., \& Paulhus, D. L. (2012). Introducing the Short Dark Triad (SD3): A brief measure of dark personalities. Journal of Research in Personality, under revision.

Jones, D. N., \& Paulhus, D. L. (2014). Introducing the short Dark Triad (SD3): A brief measure of dark personality traits. Assessment, 21(1): 28-41. pmid: 24322012. http://dx.doi.org/10.1177/1073191113514105

Jones, D. N., Paulhus, D. L. (2011). Differentiating the Dark Triad within the interpersonal circumplex. In: Horowitz, L.M., Strack, S. (editors). Handbook of Interpersonal Psychology: Theory, Research, Assessment, and Therapeutic Interventions, New York: Wiley \& 
The International Journal

ENTREPRENEURSHIP AND SUSTAINABILITY ISSUES

ISSN 2345-0282 (online) http://jssidoi.org/jesi/

2018 Volume 5 Number 4 (June)

http://doi.org/10.9770/jesi.2018.5.4(19)

Sons, $\quad$ p. 249-268. Available at:

http://www2.psych.ubc.ca/ dpaulhus/research/DARK_TRIAD/CHAPTERS/Jones\&Paulhus_2011_SITAR_\%20chapter.pdf

Judge, T.A., LePine, J.A., \& Rich, B.L. (2006). Loving yourself abundantly: Relationship of the narcissistic personality to self- and other perceptions of workplace deviance, leadership, and task and contextual performance. Journal of Applied Psychology, 91(4): 762-76. pmid: 16834504. http://dx.doi.org/10.1037/0021-9010.91.4.762

Koppelman, R. E., Mullins, L. S. (1992). Is Narcissism Inversley Related to Satisfaction? An Examination of Data from Two U.S. Samples. The Journal of Psychology, 126(2), 121-130.

Landes, D. S. (2003). Bogatstvo i siromaštvo naroda: Zašto su neki tako bogati, a neki tako siromašni. [The Wealth and Poverty of Nations: Why Some Are So Rich and Some So Poor]. Zagreb: Masmedia. ISBN: 953-157-438-3. Originally edition of W.W. Norton \& Company, New York, 1999.

Langbert, M. B. (2010). Managing Psychopatic Employees. Cornell HR Review, p. 1-7. Accessed 20 June 2018. Available at: https://digitalcommons.ilr.cornell.edu/cgi/viewcontent.cgi?article=1012\&context=chrr

Lee, K., Ashton, M. C. (2005). Psychopathy, Machiavellianism and Narcissism in the Five Factor Model and the HEXACO model of personality structure. Personality and Individual Differences, 38(7), 1571-1582. http://dx.doi.org/10.1016/j.paid.2004.09.016

Lučić, M. (2013). Istina je najvažnija: Intervju s Jackom Hawleyem. [Truth is the most important: Interview with Jack Hawley], qLife (Professional Journal for Leadership and Organizational Development), No.19-Autmn 2013, Topic of the month: Spirituality in business, October 2013, p. 45-58. Accessed 20 June 2018. Available at: http://www.quantum21.net/slike/src/2013/10/15/1381829975qlife19prew.pdf

Malesza, M., Ostaszewski, P., Büchner, S., Kaczmarek M. C. (2017). The Adaptation of the Short Dark Triad Personality Measure Psychometric Properties of a German Sample. Current Psychology: A Journal for Diverse Perspectives on Diverse Psychological Issues, Springer Verlag, p. 1-10. https://doi.org/10.1007/s12144-017-9662-0-1582

Malnick, E. (2013). Why your boss could easily be a psychopath. The Telegraph. Accessed 20 June 2018 . Available at: https://www.telegraph.co.uk/news/newstopics/howaboutthat/9828914/Why-your-boss-could-easily-be-a-psychopath.html

McHoskey, J. W., Worzel, W., \& Szyarto, C. (1998). Machiavellianism and psychopathy. Journal of Personality and Social Psychology, 74(1): 192-210. pmid: 9457782. http://dx.doi.org/10.1037/0022-3514.74.1.192

Miller, J.D., \& Lynam, D.R. (2003). Psychopathy and the Five-factor model of personality: A replication and extension. Journal of Personality Assessment, 81(2): 168-78. pmid: 12946923. http://dx.doi.org/10.1207/S15327752JPA8102_08

O'Boyle, E. R., Humphrey, R. H., Pollack, J. M., Hawver, T. H., \& Story, P. A. (2011). The relation between emotional intelligence and job performance: A meta-analysis. Journal of Organizational Behavior, 32: 788-818. https://doi.org/10.1002/job.714

O'Boyle, E.O.H., Forsyth, D.R., Banks, G.C., \& McDaniel, M.A. (2012). A meta-analysis of the Dark Triad and work behavior: A social exchange perspective. Journal of Applied Psychology, 97(3): 557-79. pmid: 22023075. https://doi.org/10.1037/a0025679

Ozimec, S. (2001). Naši mentaliteti. [Our mentality - in Croatia]. Varaždinske Topice: Tonimir. Bibilioteka posebna izdanja. ISBN: 9536338-81-5.

Pastuović, N. (1999). Edukologija: integrativna znanost o sustavu cjeloživotnog obrazovanja i odgoja [Educology: the integral science about the system of lifelong education]. Zagreb: Znamen. ISBN: 953-6008-04-1.

Paulhus, D. L., \& Jones, D. N. (2011). Introducing a short measure of the Dark Triad. Poster presented at the meeting of the Society for Personality and Social Psychology, San Antonio, USA. Retrieved from www.midss.ie. Accessed 20 June 2018. Available at: http://www.midss.org/sites/default/files/d3.pdf

Paulhus, D. L., \& Williams, K. M. (2002). The Dark Triad of Personality: Narcissism, Machiavellianism and Psychopathy. Journal of Research in Personality, 36: 556-563. https://doi.org/10.1016/S0092-6566(02)00505-6

Plumridge, N. (2013). The Dark Triad. Accessed 20 June 2018. Available at: http://psychminds.com/the-dark-triad/ 
Samnani, A. (2013). Embracing New directions in Workplace Bullying Research: A Paradigm Approach. Journal of Management Inquiry, 22(26): 26-36. https://doi.org/10.1177/1056492612451653

Siller, H., Cibak, L. (2016). Korruption und ihre gesamtwirtschaftliche Bedeutung, in: Kriminalistik-Osterreich, 1/2016, ISBN: 978-37832-0804-7.

Spain, S., Harms, M., Lebreton, J. M. (2013). The Dark Side of Personality at Work. Management Department Faculty Publications, University of Nebraska - Lincoln. Available at: http://digitalcommons.unl.edu/managementfacpub/99

XY (under revision). Assessing personality quickly and efficiently-psychometric evaluation of the Dark Triad „Dirty Dozen“ measure for German adolescents, Polish Psychological Bulletin.

Yatzeck, E. (2012). Beware the Dark Triad: Your Worst Change Management Nightmare. Pragmatic Agilist. Accessed 20 June 2018. Available at: http://pagilista.blogspot.ae/2012/12/beware-dark-triad-your-worst-change.html

Zuroff, D. C., Fournier, M. A., Patall, E. A., Leybman, M. J. (2010). Steps toward an evolutionary personality psychology: Individual differences in social rank domain. Canadian Psychology, 51: 58-66 https://doi.org/10.1037/a0018472

Mario BOGDANOVIĆ, Docent, PhD\&MSc\&BSc Economics, BSc Psychology, senior research associate, has been employed in business, primary, secondary, college study level and from 01 February 2008. to 31 January 2018. on Faculty of Economics University in Split, on the Management Department, Croatia. On the ground of achieved grant of Slovak government was visiting professor, teacher and researcher (docent, senior research associate) at Faculty of Economics Matej Bell University in Banská Bystrica in summer semester 2015/2016. His professional area of interest is general management, human resources management (HRM), organizational behaviour, strategic management, strategies of new product, business ethics, entrepreneurship. He published about 65 scientific and professional papers. As visiting professor he taught also in several European countries in the topics of business ethics, HRM, organizational behaviour, entrepreneurship. He was active in several scientific projects, and was leader for introducing new study programs and courses on master level in the area of organization and management.

ORCID ID: https://orcid.org/0000-0003-3049-5342

Milota VETRAKOVA, prof. Ing. PhD. is professor on public Faculty of Economics Matey Bel University in Banska Bystrica, Republic of Slovakia employed from 01 September 1975 until now. Her main duties and responsibilities were: courses of human resources management, courses of managerial communication, communication skills - training, research in the field of human resources, member of state exams, author, co-author, member of science committees, member of programme committees of conferences, expert of managing of human resources as dean of Faculty of Economics Matej Bel University (from1994 to 2000, 2003 - 2007), vice dean for pedagogical study Faculty of Economics MBU(1990-1994, 2000-2003), study stay in Regional National Council (1978), vice rector for pedagogical study (2007 up to December 2014). Now is professor on the Department of Tourism and Hospitality Management Faculty of Economics University Matey Bel in Banska Bystrica.

ORCID ID: $\underline{\text { https://orcid.org/0000-0001-7837-5118 }}$

Stanislav FILIP, Assoc prof. Ing. PhD. is the Vice-Rector for foreign affairs an teacher of the School of Economics and management in Public Administration in Bratislava. His text books, monographs and scientific papers deal with the Risk and crisis managemtn in public sector, international crisis management and public administration at the national and EU level. He is succesfull leader and manager of the several scientific projects with support from the EU structural funds. He also organise and control international colaboration and Erasmus plus program with the high educational and research institutions in abroad.

ORCID ID: https://orcid.org/0000-0003-3000-9383

Copyright (C) 2018 by author(s) and VsI Entrepreneurship and Sustainability Center

This work is licensed under the Creative Commons Attribution International License (CC BY).

http://creativecommons.org/licenses/by/4.0/

(c) (i) Open Access 